\title{
Synthesis of Functionalized Single graphene Sheets by thermal exfoliation of Graphite Oxide
}

\section{ABDUL JABAR MOHMMED SALEH AL-EYANI ${ }^{3}$ and NABIL ABDULLAH NOMAN ALKADASI ${ }^{1,2,3}$}

\author{
${ }^{1}$ Hubei Key Lab of Materials Chemistry \& Service Failure, School of Chemistry \& Chemical \\ Engineering, Huazghog University of Science and Technology, Wuhan, Hubei, 430074 China . \\ 2Department of Chemistry, Faculty of Education, Al-baida'a, University, Yemen , P.O.Box:39189. \\ ${ }^{3}$ Mechanical Engineering, Faculty of Engineering,Thamar University, Yemen. \\ *Corresponding author E-mail: nalkadasi@yahoo.com
}

http://dx.doi.org/10.13005/ojc/300405

(Received: September 24, 2014; Accepted: November 03, 2014)

\begin{abstract}
Synthesis is described to produce single sheets functionalized graphene through thermal exfoliation of graphite oxide. Synthesis yields a single sheet structure resulting from the reaction sites involved in oxidation and reduction process. Application of graphite used for unelectrical material and used pencil meanwhile main applications of graphene sheets are electrical materials.
\end{abstract}

Key words: Graphite, Graphene oxide and Graphene sheets, Characterization and application.

\section{INTRODUCTION}

Graphene is a single hexagonally flat layer of graphite, which has attracted great interest both for fundamental understanding of its unique structural and electronic properties and for important potential applications in nano-electronics and devices ${ }^{1-6}$. The unique properties of this twodimensional (2D) material include the highest intrinsic carrier mobility at room temperature of all known materials and very high mechanical strength and thermal stability ${ }^{7-10}$. Graphene holds great promise for the development of new composite materials, emissive displays, ultrasensitive detectors and micromechanical resonators ${ }^{11-13}$. The combination of high mobility, thermal, chemical and mechanical stability with the high surface area offers many interesting applications in a wide range of fields including heterogeneous catalysis where metallic and bimetallic nano-particle catalysts can be efficiently dispersed on the graphene sheets ${ }^{14-}$ ${ }^{16}$. In many cases, the remarkable properties of single graphene layers extend to bilayers and a few layers of graphene sheets. Several methods have been reported for the production of graphene sheets including micromechanical cleavage and thermal expansion of graphite . 


\section{EXPERIMENTAL}

\section{Materials}

Physical parameters of Graphite $99.95 \%$, Potassium Chlorite, Sulfuric acid $\mathrm{H}_{2} \mathrm{SO}_{4}$ and Nitric acid $\left(\mathrm{HNO}_{3}\right), 99.9 \%$ are reported in table 1, 2 ,3 and 4 respectively.

\section{Fabrication of graphene sheets}

Commercial powdered natural graphite (from Aladdin Industrial Corporation Shanghai, China ) was used as our starting material. The commercial graphite has a particle size of 325 mesh with a purity of $99.99 \%$. Graphite was oxidized following modified Method of Staudenmaier method to form graphite oxide (GO). In this method, graphite $(2.5 \mathrm{~g})$ was first mixed with sulfuric acid $(43.75 \mathrm{~mL})$ and nitric acid $(22.5 \mathrm{~mL})$ and stirred. When graphite was uniformly dispersed, potassium chlorate $(27.5 \mathrm{~g})$ was added slowly and stirred for over $96 \mathrm{~h}$. After the completion of oxidation reaction, the mixture was added into $4 \mathrm{~L}$ deionized water and then filtered. The GO was repeatedly rinsed and redispersed in a $5 \%$ solution of $\mathrm{HCl}$. It was then washed continually with deionized water until the $\mathrm{pH}$ of the filtrate was neutral ${ }^{17-33}$. Potassium stayed in the GO even after several times of washing .Therefore multiple washing cycles used in conjunction with bath ultrasonication in fresh ethanol were used for the removal of residual potassium . After this the GO was dried in a vacuum oven at $60^{\circ} \mathrm{C}$ until used. Finally, the $\mathrm{GO}$ was treated with the nitrogen $\left(\mathrm{N}_{2}\right)$ and then it was heated to $1050^{\circ} \mathrm{C}$ in the furnace for $30 \mathrm{~s}$ to form graphene sheets $^{16-31}$.

\section{Treatment silicon wafer}

silicon wafer were cut into ( $3 \mathrm{~mm} \times 3 \mathrm{~mm}$ ) used Piranha solution is mixture consisting of sulfuric acid $\left(\mathrm{H}_{2} \mathrm{SO}_{4}\right)$ and hydrogen peroxide $\left(\mathrm{H}_{2} \mathrm{O}_{2}\right)$ is to cleaning silicon wafer. It is typically mixed in concentration ratios of around $3: 1 \mathrm{H}_{2} \mathrm{SO}_{4}: \mathrm{H}_{2} \mathrm{O}_{2}$ for one hour with temperature $60{ }^{\circ} \mathrm{C}$. Then followed by triple rinsing in ethanol with ultrasonic cleaning for 30 min then with nitrogen $\left(\mathrm{N}_{2}\right)$. There are two main applications for piranha in wafer fabrication: it is used to remove organic contaminants from surface of the wafer during cleaning. Silicon wafer were used for SEM ${ }^{32}$.

\section{RESULTS AND DISCUSSION}

The GO was reduced to graphene sheet by heating to $1150^{\circ} \mathrm{C}$. Plate 1,2 ( SEM ) and plate 7 (TEM) shows the top-view TEM images of the graphite oxide plate ( SEM ) 3, 4 and plate 8 (TEM). TEM images of the original graphite plate

Table 1: General Characteristics of Graphite $99.95 \%$

\begin{tabular}{ll}
\hline Trade Name & Graphite $\mathbf{9 9 . 9 5 \%}$ \\
\hline Appearance & Black \\
Size & 325 mesh \\
Company & Aladdin Industrial Corporation \\
& Shanghai, China \\
\hline
\end{tabular}

Table 2: General characteristics of Potassium Chlorate

\begin{tabular}{ll} 
Trade Name & $\mathrm{KClO}_{3}$ \\
\hline Appearance & White \\
Molecular weight & 122.55 \\
Company & China \\
\hline
\end{tabular}

Table 3: General Characteristics of Sulfuric Acid $\mathrm{H}_{2} \mathrm{SO}_{4}$

\begin{tabular}{ll}
\hline Molecular formula & $\begin{array}{l}\text { Sulfuric Acid }\left(\mathrm{H}_{2} \mathrm{SO}_{4}\right) \\
, 99.9 \%\end{array}$ \\
\hline Appearance & liquid \\
Molecular weight & 98.08 \\
Concentration & $95-98 \%$ \\
Company & Sinopharm chemical \\
& reagent Co ,Ltd ,China \\
\hline
\end{tabular}

Table 4. General Characteristics of Nitric Acid ( $\left.\mathrm{HNO}_{3}\right), 99.9 \%$

\begin{tabular}{ll} 
Molecular formula & Nitric $\mathrm{Acid}\left(\mathrm{HNO}_{3}\right), 99.9 \%$ \\
\hline Appearance & liquid \\
Molecular weight & 63.01 \\
Concentration & $65-68 \%$ \\
Company & Sinopharm chemical \\
& reagent Co ,Ltd ,China \\
\hline
\end{tabular}




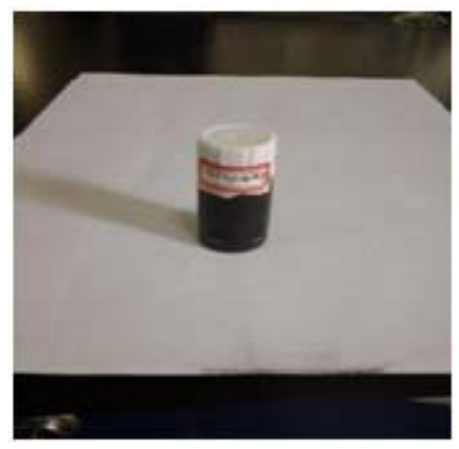

Photo 1: Graphite in water

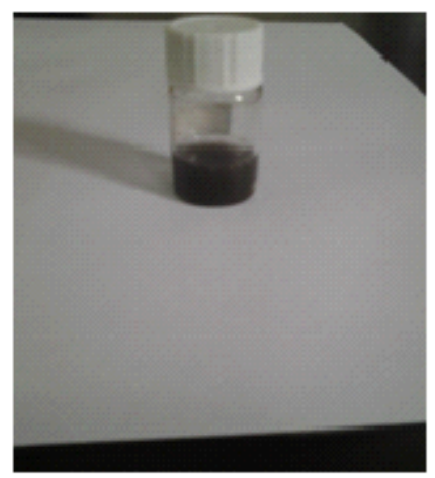

Photo 3: Graphene Sheet in water
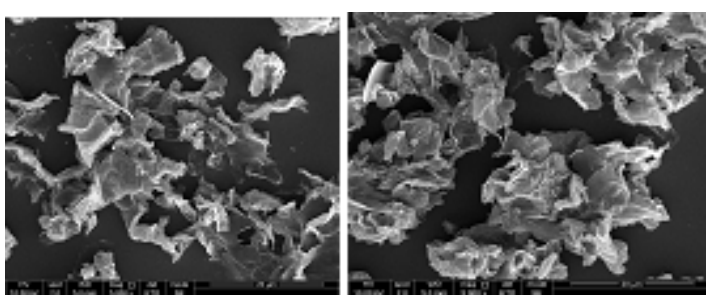

Plate 2: SEM of Graphene sheets dispersed in ethanol

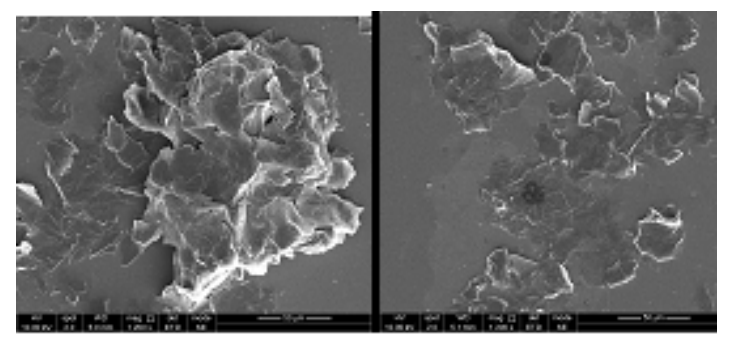

Plate 4: SEM of Graphene Oxide ( Dry ) dispersed in ethanol
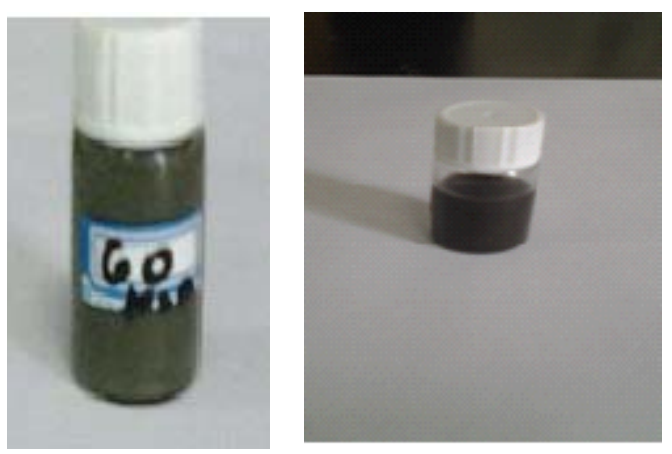

Photo 2: GO green before dry GO.dry in $60^{\circ} \mathrm{C}$ water

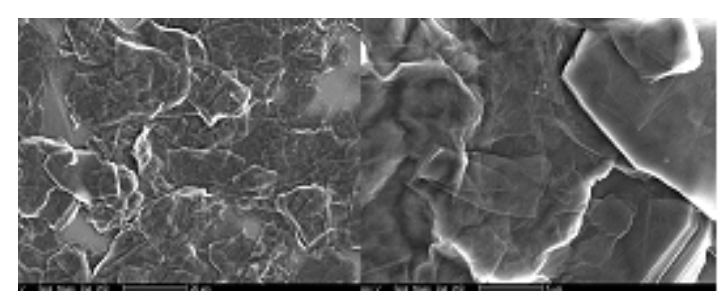

Plate 1: SEM of Graphene sheets dispersed in water

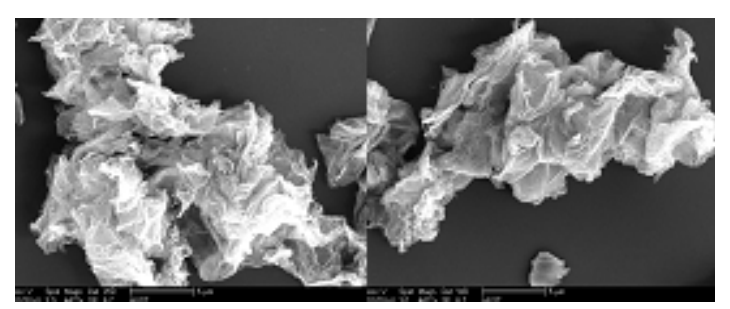

Plate 3: SEM of Graphene Oxide (Dry) dispersed in water

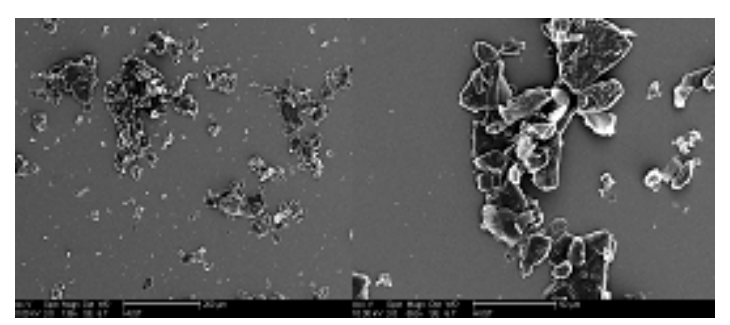

Plate 5: SEM of Graphite dispersed in water 


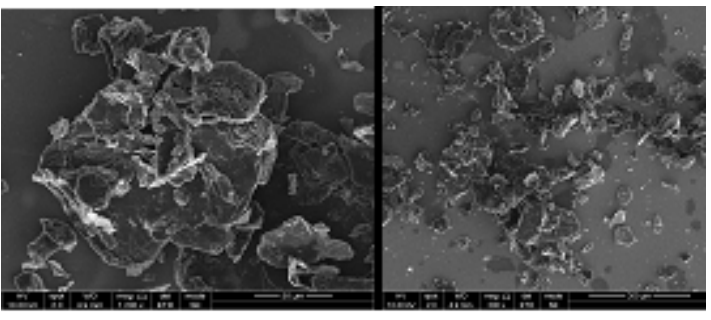

Plate 6: SEM of Graphite dispersed in ethanol

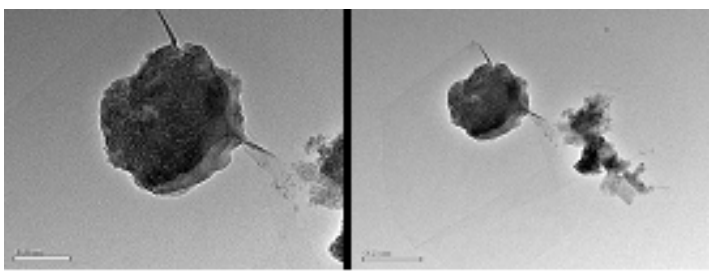

Plate 8: TEM of Graphene Oxide

(SEM ) 5,6 and plate 9 (TEM ). A small flake of graphite particle is seen in .The size of the graphene sheet is about $9.35 \mu \mathrm{m}$ from SEM photo. The surface of graphene shows several large meandering wrinkles. The thickness of graphene can be clear in high-magnification TEM image.

\section{CONCLUSIONS}

Single sheets functionalized graphene through thermal exfoliation of graphite oxide. Main

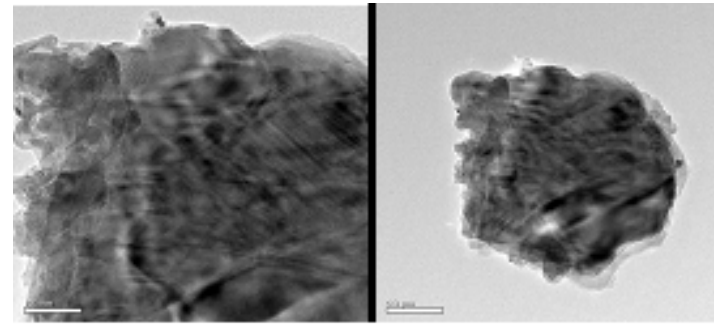

Plate7: TEM of Graphene sheets

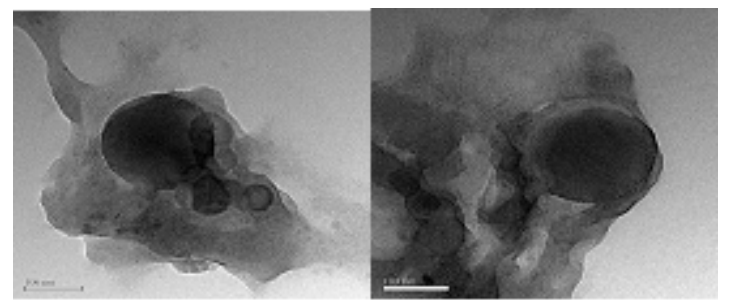

Plate 9: TEM of Graphite

application of graphene sheets in electrical material. The surface of graphene sheets shows several large meandering wrinkles. The thickness of graphene can be determined from the high-magnification TEM image.

\section{ACKNOWLEDGEMENTS}

I acknowledge the financial support from UNESCO/Government of China (Great wall) and Al-baida'a ,University , Yemen .

\section{REFERENCES}

1. K.S .Novoselov, A.K .Geim, S.V. Morozov, D. Jiang, Y. Zhang, S.V .Dubonos, et al. Electric field effect in atomically thin carbon films. Science 2004; 306: 666-9.

2. Novoselov KS, Jiang D, Schedin F, Booth TJ, Khotkevich VV, Morozov SV, et al.Twodimensional atomic crystals. Proc Natl Acad Sci USA 2005;102: 10451-3.

3. Geim AK, Novoselov KS. The rise of graphene. Nat Mater 2007; 6:183-91.

4. Novoselov KS, Geim AK, Morozov SV, Jiang D, Zhang Y, Dubonos SV, et al. Twodimensional gas of massless Dirac fermions in grapheme. Nature 2005; 438 : 197-202.
5. Partoens B, Peeters FM. From graphene to graphite: electronic structure around the $\mathrm{K}$ point. Phys Rev B 2006; 74: 075404.

6. Ghorbani, H.R., Orient J Chem., 2014, 30(2), 803-806.

7. Graf D, Molitor F, Ensslin K, Stampfer C, Jungen A, Hierold $C$, et al. Spatiallyresolved Raman spectroscopy of single- and fewlayer graphene. Nano Lett 2007;7:238-42.

8. Stankovich S, Dikin DA, Dommett GHB, Kohlhaas KM, Zimney EJ, Stach EA, et al. Graphene-based composite materials. Nature 2006; 442: 282-6.

9. McAllister MJ, Li JL, Adamson DH, Schniepp $\mathrm{HC}$, Abdala AA, Liu J, et al. Single sheet 
functionalized graphene by oxidation and thermal expansion of graphite.Chem Mater 2007;19: 4396-404.

10. Stankovich S, Piner RD, Nguyen ST, Ruoff RS. Synthesis and exfoliation of isocyanatetreated graphene oxide nanoplatelets. Carbon 2006; 44: 3342-7.

11. Stankovich S, Piner RD, Chen X, Wu N, Nguyen ST, Ruoff RS. Stable aqueous dispersions of graphitic nanoplatelets via the reduction of exfoliated graphite oxide in the presence of poly(sodium 4styrenesulfonate). J Mater Chem 2006; 16: $155-8$.

12. Li X, Zhang G, Bai X, Sun X, Wang X, Wang $E$, et al. Highly conducting graphene sheets and Langmuir-Blodgett films. Nat Nanotechnol 2008; 3: 538-42.

13. Hernandez Y, Nicolosi V, Lotya M, Blighe FM, Sun ZY, De S, et al. High-yield production of graphene by liquid-phase exfoliation of graphite. Nat Nanotechnol 2008; 3: 563-9.

14. Lotya M, Hernandez Y, King PJ, Smith RJ, Nicolosi V, Karlsson LS, et al. Liquid phase production of graphene by exfoliation of graphite in surfactant/water solutions. J Am Chem Soc 2009; 131: 3611-20.

15. Pu NW, Wang CA, Sung Y, Liu YM, Ger MD. Production of few-layer graphene by supercritical $\mathrm{CO}_{2}$ exfoliation of graphite. Mater Lett 2009;63:1987-9.

16. Liu N, Luo F, Wu H, Liu Y, Zhang C, Chen J. One - step ionic - liquid - assisted electrochemical synthesis of ionic-liquidfunctionalized graphene sheets directly from graphite. Adv Funct Mater 2008;18:151825.

17. Li D, Mu“ Iler MB, Gilje S, Kaner RB, Wallace GG. Processable aqueous dispersion of graphene nanosheets. Nat Nanotechnol 2008; 3:101-5.

18. Liu Z, Robinson JT, Sun X, Dai H. PEGylated nano-graphene oxide for delivery of water insoluble cancer drugs. J Am Chem Soc 2008;130:108767.

19. Wu H, Wang J, Kang X, Wang C, Wang D, Liu J, et al. Glucose biosensor based on immobilization of glucose oxidase in platinum nanoparticles/graphene/chitosan nanocomposite film. Talanta 2009; 80(1):
403-6.

20. Stoller MD, Park S, Zhu Y, An J, Ruoff RS. Graphene-based ultracapacitors. Nano Lett 2008; 8: 3498-502.

21. Hsiao MH, Liao SH, Yen MY, Teng CC, Lee $\mathrm{SH}, \mathrm{Pu} \mathrm{NW}$, et al. Preparation and properties of a graphene reinforced nanocomposite conducting plate. J Mater Chem 2010; 20:8496-505.

22. Liu Y, Ren L, He Y, Cheng HP. Titaniumdecorated graphene for high-capacity hydrogen storage studied by density functional simulations. J Phys Condens Matter 2010; 22: 445301.

23. Schniepp HC, Li JL, McAllister MJ, Sai H, Herrera-Alonso M, Adamson DH, et al.Functionalized single graphene sheets derived from splitting graphite oxide. J Phys Chem B 2006;110: 8535-9.

24. Viculis LM, Mack JJ, Mayer OM, Hahn HT, Kaner RB. Intercalation and exfoliation routes to graphite nanoplatelets. J Mater Chem 2005; 15: 974-8.

25. Elias DC, Nair RR, Mohiuddin TMG, Morozov SV, Blake P, Halsall MP, et al.Control of graphene's properties by reversible hydrogenation: evidence for graphane. Science 2009; 323: 610-3.

26. Rao CNR, Biswas K, Subrahmanyam KS, Govindaraj A. Graphene, the new nanocarbon. J Mater Chem 2009;19:245769.

27. Saito R, Fujita M, Dresselhaus G, Dresselhaus MS. Electronic structure of chiral graphene tubules. Appl Phys Lett 1992; 60: 2204-6.

28. Liang Y, Wu D, Feng X, Mu“ llen K. Dispersion of graphene sheets in organic solvent supported by ionic interactions. Adv Mater 2009;21:1679-83.

29. Li D, Muller MB, Gilje S, Kaner RB, Wallace $\mathrm{GG}$. Processable aqueous dispersions of graphene nanosheets. Nat Nanotechnol 2008; 3: 101-5.

30. Paredes JI, Villar-Rodil S, Mart1'o' nezAlonso A, Tasco'n JMD. Graphene oxide dispersions in organic solvents. Langmuir 2008; 24:10560-4.

31. Li JT, Li M, Li JH, Sun HW. Removal of disperse blue $2 \mathrm{BLN}$ from aqueous solution 
by combination of ultrasound and exfoliated graphite. Ultrason Sonochem 2007;14:626.

32. Shen J, Hu Y, Li C, Qin C, Ye M. Synthesis of amphiphilic graphene nanoplatelets. Small 2009; 5: 82-5.
33. Yizhi W, Cheng Z, Ye Y, Ziwen W, Weijia S, Huijie W and Xiaoliang $X$. Fabrication of wafer - Zize Monolayer close -packed colloidal crystals via slope self -assembly and thermal treatment . Langmuir 2013; 29: 1401714023. 